\title{
Simulation Study of Three Types of Distributed Power Based on EMTDC
}

\author{
Peng-tao Mu, Dong-mei Zhao \\ School of Electrical and Electronic Engineering, North China Electric Power University, Beijing, China \\ Email: mupengtao0328@163.com
}

Received March, 2013

\begin{abstract}
In order to analyze the performances of directly-driven permanent magnet synchronous generator wind turbine (PMSG) connecting to the grid, photovoltaic array and microtubine, dynamic models of them are established. The validity of the established models and proposed control strategies are demonstrated by simulation system under the software package PSCAD/EMTDC.
\end{abstract}

Keywords: Wind Power; Photovoltaic; Microtubine; Simulation; PSCAD/EMTDC

\section{Introduction}

Distributed generation refers to making use of a variety of decentralized energy, including renewable energy and the local fossil fuel which is easy to get to generate power. Flexible, economic, and environmental protection are the main advantages of distributed generation. But at the same time some of the renewable energy have inter- mittent and randomness characteristics, this power has some difficulties to regulate itself alone to meet the load, usually need other power to coordinate [1]. Currently, more mature distributed generation technologies have several forms, such as photovoltaic power, wind power, gas turbine power.

Grid connection of the distributed power has presented new challenges to the safe operation of the power system. The diversity of distributed power increases the difficulty to connect the grid. Grid-connected distributed power easily affect the quality of the surrounding electricity users, it is difficult to achieve energy optimization.

About wind power generation system, synchronous wind turbines which is connected to the grid by uncontrollable rectifier and controllable grid-connected inverter is studied in the literature [2]. A method to decouple the power of D-PMSG (directly driven wind turbine with permanent magnet synchronous generators) which is connected to the grid by uncontrollable rectifier and controllable inverter is reported in literature [3]. A complete model of the PMSG is given in literature [4]. About photovoltaic power generation system, a photovoltaic

*The National High Technology Research and Development of China 863 Program (2012AA050201). cell model with a friendly interface is developed using Matlab/Simulink simulation software in literature [5]. A simple photovoltaic generation systems is established using PSCAD/EMTDC electromagnetic transient simulation software in literature [6]. About micro turbine generation system, a single cycle mathematical model for dynamic simulation of microturbine is established on the basis of the analysis of single cycle overloaded microturbine in the literature [7].

\section{Model Research of Wind Power Generation System}

\subsection{Structure of Wind Power Generation System}

A complete distributed generation system is mainly composed of distributed power, power electronic converter, the various controllers as well as the power grid or load. These components require modeling and solving in the electrical and control system.

The modeling of doubly fed induction wind generator has been a lot of research at home and abroad, relatively modeling of directly driven wind turbine with permanent magnet synchronous generator is less. A permanent magnet synchronous generator is used in this article. The overall structure of the wind generation system is shown in Figure 2-1. Many articles have the detailed introduction about the wind turbine and grid-connected converter, so these parts are ignored.

\subsection{Modeling of Directly-Driven Permanent Magnet Synchronous Generator}

Permanent magnet synchronous generator for wind power 
has more pole pairs, so the generator can still work in low rotor speed, thus permanent magnet synchronous generator can directly couple to the wind turbine, eliminating the need for a gear box. A mathematical model of permanent magnet synchronous generator is established in $\mathrm{d}-\mathrm{q}$ synchronous rotating coordinate system:

$$
\begin{aligned}
& u_{d}=-R_{s} i_{d}+w L_{q} i_{q}-L_{d} \frac{d i_{d}}{d t} \\
& u_{q}=-R_{s} i_{q}-w L_{d} i_{d}+w \psi_{f}-L_{q} \frac{d i_{q}}{d t} \\
& T_{e}=\frac{3}{2} p i_{q}\left[-i_{d}\left(L_{d}-L_{q}\right)+\psi_{f}\right]
\end{aligned}
$$

$u_{d}$ is the d-axis voltage of generator unit stator; $u_{q}$ is the q-axis voltage of generator unit stator; $i_{d}$ is the d-axis current of generator unit stator; $i_{q}$ is the q-axis current of generator unit stator; $L_{d}$ is the d-axis equivalent inductance of generator unit stator; $L_{q}$ is the q-axis equivalent inductance of generator unit stator; $R_{s}$ is stator armature winding resistance; $\psi_{f}$ is the permanent magnet flux of rotor; $T_{e}$ is the electromagnetic torque; $w$ is the frequency of the stator electrical angle; $p$ is the number of pole pairs.

\subsection{Control Strategy of Grid-Connected Inverter}

The main role of the grid-connected inverter is to maintain voltage of dc side constant, and to control the reactive power exchange between the wind driven generator and the grid according to need of the grid[8]. Shown in Figure 2-2.

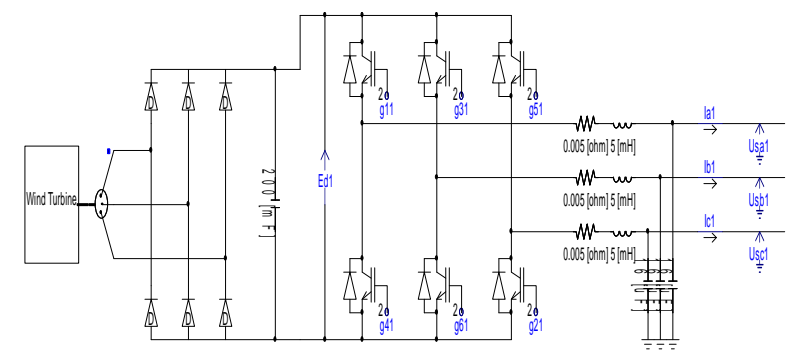

Figure 2-1. The overall structure of the wind power generation system.

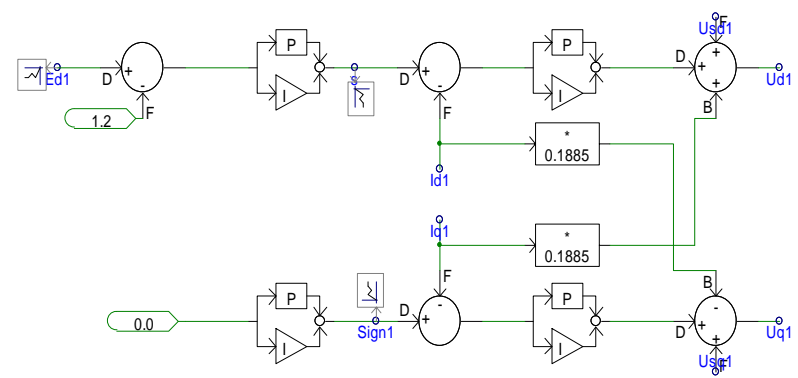

Figure 2-2. The control of grid-connected inverter.
Active and reactive power output of the gridconnected inverter:

$$
\begin{aligned}
& P_{1}=u_{d 1} i_{d 1}+u_{q 1} i_{q 1} \\
& Q_{1}=u_{q 1} i_{d 1}-u_{d 1} i_{q 1}
\end{aligned}
$$

The grid voltage space vector is put on d-axis on the d-q coordinate system, so $u_{d 1}=u_{g} 、 u_{q 1}=0$. We can get that $P_{1}=u_{d 1} i_{d 1} 、 Q_{1}=-u_{d 1} i_{d 1}$, apparently, you can achieve decoupling control of active and reactive power through the control of $i_{d 1}$ and $i_{q 1}$.

\section{Simulation Model of Photovoltaic Generation System}

Grid-connected PV system is made up of the PV array, DC / DC converter, inverter and other components, and the most important components are the PV array and inverter. The photovoltaic generation system is shown in Figure 3-1.

\section{Simulation Model of Microtubine}

Microturbine generation system [9] is mainly composed of the microturbine of high-speed rotation and permanent magnet synchronous generator. microturbine is made up of micro-turbine compressor, combustor, gas turbine. The mixture of the pressurized air by the compressor and fuel flame in the combustion chamber, and the high temperature gas expands in the gas turbine to generate power, which eventually converted to mechanical energy. A part of the mechanical energy drive compressor work, the other part is provided to the generator. The velocity, temperature, and fuel control the air quantity which is sent into the combustor to limit the upper temperature of the combustion chamber in order to obtain maximum operating efficiency in a safe and reliable state in the energy conversion process .The microturbine model is shown in Figure 4-1.

\section{Simulation}

\subsection{Wind Generation System}

Wind power generation and transmission system which is

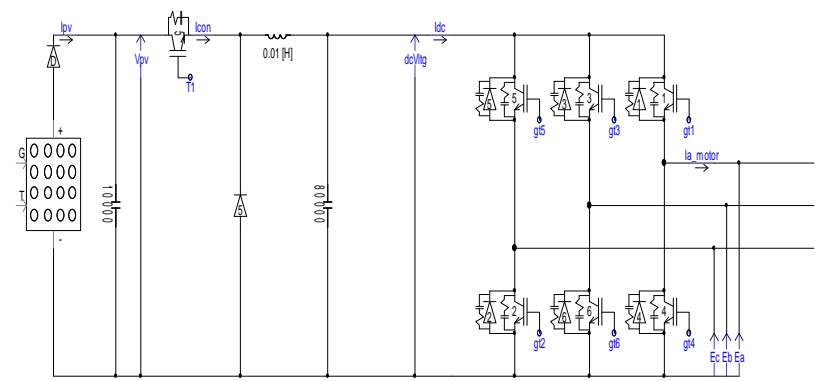

Figure 3-1. The structure of the photovoltaic generation system. 


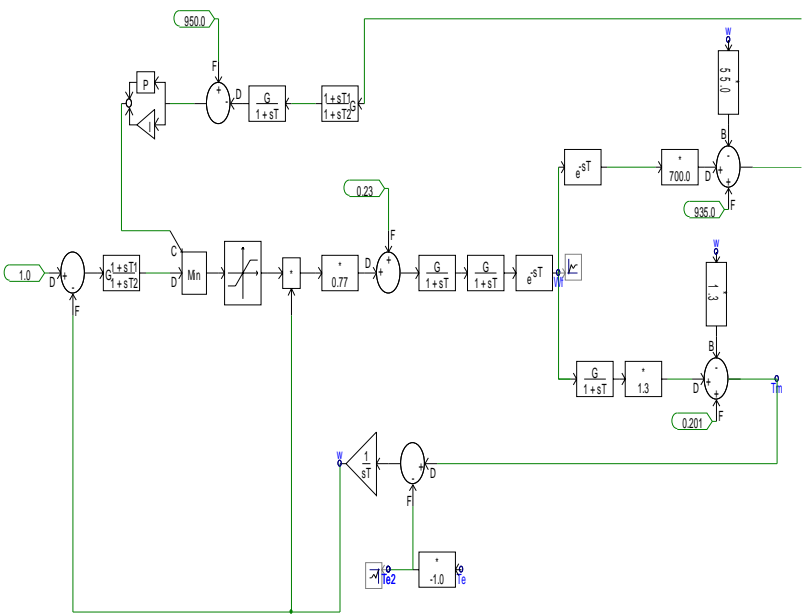

Figure 4-1 The structure of the photovoltaic generation system.

shown in Figure 2-1 is set up in the PSCAD / EMTDC simulation platform to simulate the changes of power and voltage under the gust. The wind turbine in the system is a directly driven wind turbine with permanent magnet synchronous generator.

In the simulation example, the start average wind speed to is $4 \mathrm{~m} / \mathrm{s}$, after 5 seconds, the speed reduces to $1.98 \mathrm{~m} / \mathrm{s}$. The total simulation time is $20 \mathrm{~s}$, and the solution time step is $50 \mu \mathrm{s}$. The simulation results are shown in Figure 5-1, Figure 5-1(a) shows the generator speed can quickly follow the changes of the wind turbine. Figure 5-1(b) shows the active power generator issue can quickly follow the variation of the wind turbine. we can see that the capacitor voltage of DC side fluctuates because of changes in the system transmit power from Figure 5-1 (c). We can get the following conclusions, this wind power system can operate stable under different wind conditions. The grid converter of this system uses PI controllers, which does not require complex mathematical algorithms. The control method is simple and the dynamic performance of control system is good.

\subsection{Photovoltaic Generation System}

As shown in Figure 3-1, the system is based on photovoltaic arrays for power, and the power flow to the DC load through buck circuit. The MPPT module realtime calculates and output voltage of the maximum power. The voltage is compared with the capacitor voltage of DC side to generate a PWM control signal. The signal adjusts the output voltage of the PV array to make the PV array work in the maximum power point voltage, so the $\mathrm{PV}$ array output power reaches the maximum. Using incremental conductance method in MPPT, incremental conductance method achieves maximum power tracking through instantaneous conductance and conductance change.

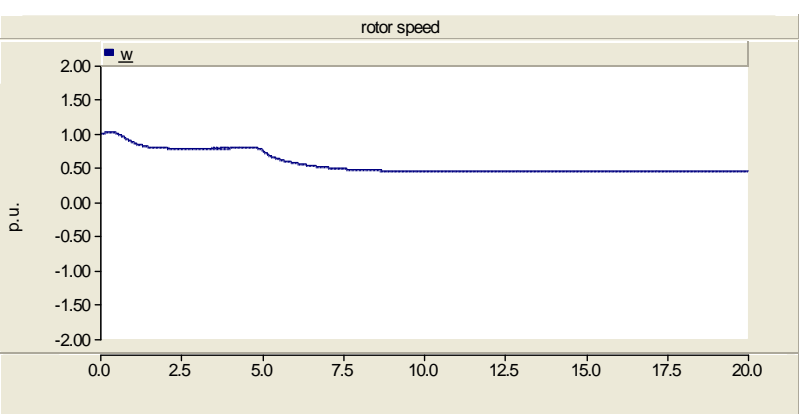

(a)

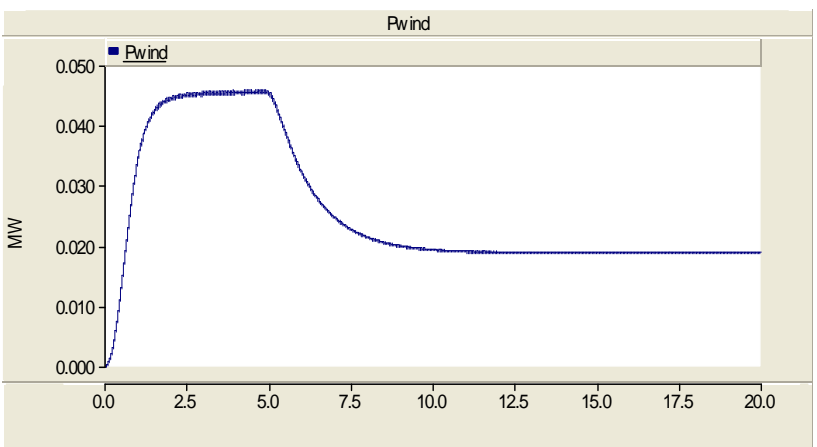

(b)

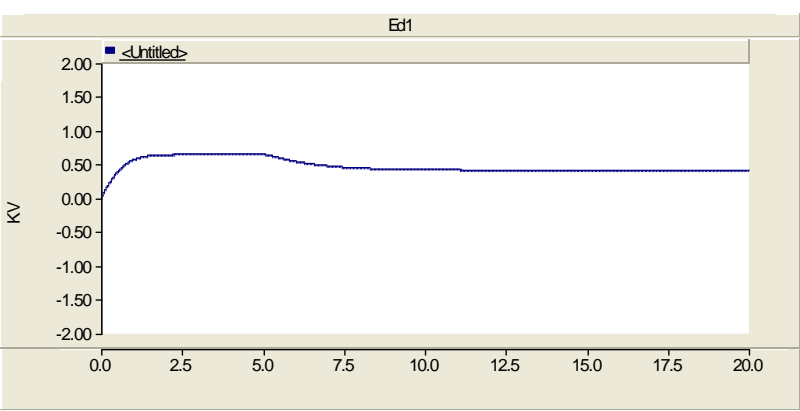

(c)

Figure 5-1. (a) Generator speed; (b) Generator active power; (c) capacitor voltage of DC side.

In the simulation example, the first light intensity of $1000 \mathrm{w} / \mathrm{m}^{2}$, after 5 seconds, the light intensity reduced to $460 \mathrm{w} / \mathrm{m}^{2}$, the total simulation time is $7 \mathrm{~s}$, the solution time step is $50 \mu \mathrm{s}$.

From the Figure 5-2, the system will soon enter the steady state; this is because the photovoltaic array module does not contain the dynamic links, when the changes of the light intensity, the system can well adjust the active power and the photovoltaic outlet voltage. Because of MPPT control, the output voltage remains near the maximum power point. When the light intensity drops from $1,000 \mathrm{w} / \mathrm{m}^{2}$ to $460 \mathrm{w} / \mathrm{m}^{2}$, the output voltage of the PV array decreases at the beginning and then increases, but the size is almost no change, This is the PV characteristics curve with the light intensity changes and changes in the law exactly. The change rule of Figure5-2 is exactly similar to the rule of $\mathrm{P}-\mathrm{V}$ 
characteristics curve of the light intensity changing.

\subsection{Microturbine Generation System}

Microturbine generation system which is shown in Figure 5-3 is set up in the PSCAD / EMTDC simulation platform to simulate the operating characteristics of the microturbine. Microturbine provides power to the load of $40 \mathrm{kw}$. The total simulation time is $20 \mathrm{~s}$, and the solution time step is $50 \mu \mathrm{s}$. Power characteristic of microturbine is shown in Figure 5-4.

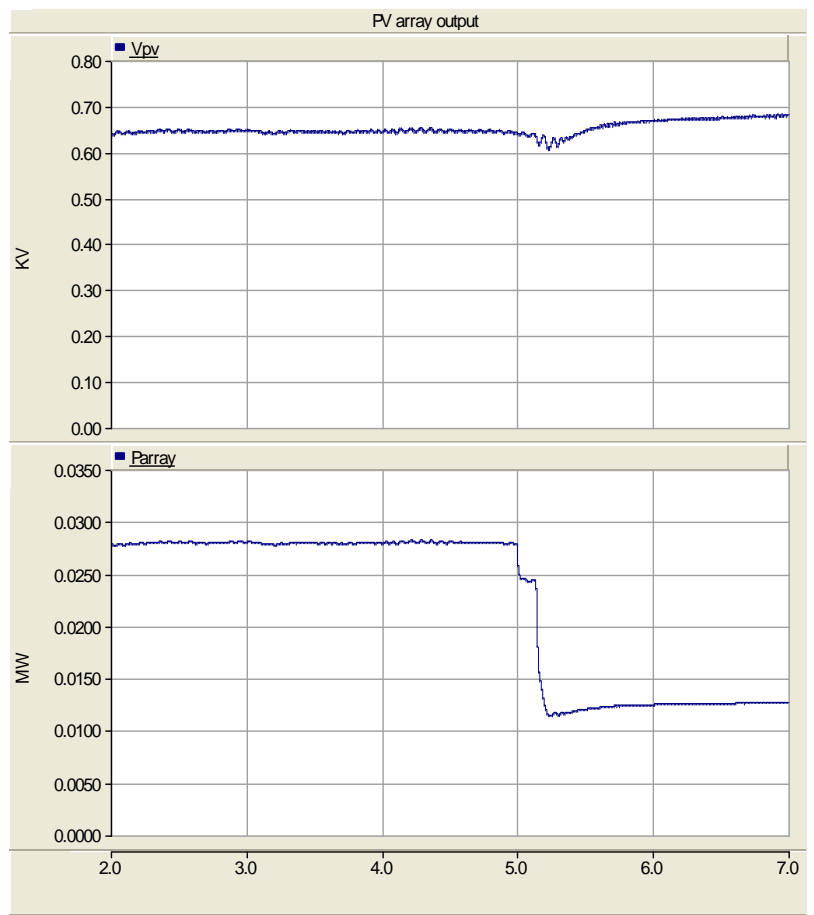

Figure 5-2. PV array output voltage, PV array output power.

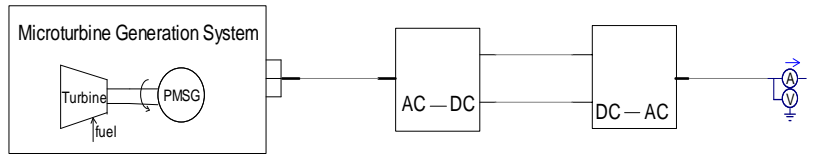

Figure 5-3. microturbine power generation system structure.

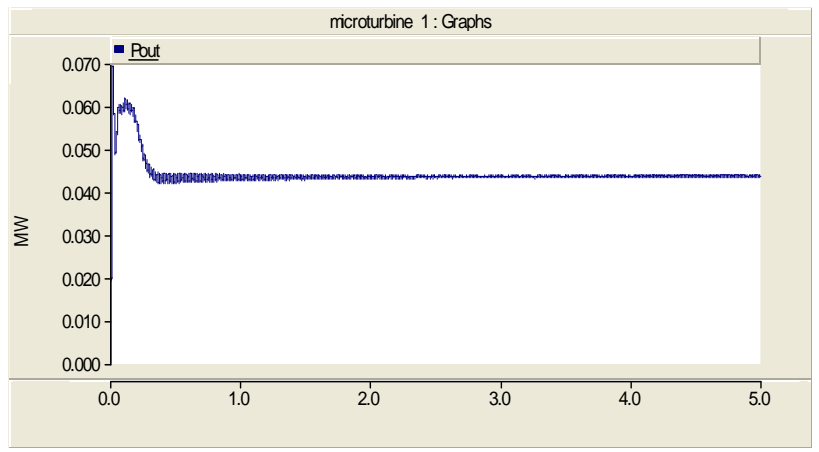

Figure 5-4. active power of microturbine.

\section{Conclusions}

The grid-connected model of directly driven wind turbine with permanent magnet synchronous generator is established based on PSCAD/EMTDC simulation platform. The model achieves maximum wind energy capture and the dynamic performance is good.

Characteristics of the PV array are related to the parameters of photovoltaic cell module, and are also related to the intensity of solar radiation and ambient temperature, thus the PV array is actually a highly nonlinear power with multiple parameters. A mathematical model based on the physics of the photovoltaic cell is build in PSCAD, and the result of simulation shows that the above model can dynamically track changes of the intensity of solar radiation and other parameters.

Microturbine power generation system consists of microturbine mover system, high-speed permanent magnet synchronous generator and power electronic converter. This article briefly describes the microturbine mover system. Simulation results show that the structure of the system is able to simulate the steady-state process of the microturbine. The model can be used as the basis of the following study.

\section{REFERENCES}

[1] P. Li, "Research on the Transient Simulation Methodology of Micro-grid Powered by Distributed Energy Resources,” Ph.D. Thesis, Tianjin University, 2010.

[2] S. K. Kim, E. S. Kim and J. Y. Yoon, "PSCAD/EMTDC Based Dynamic Modeling and Analysis of a Variable Speed Wind Turbine,” IEEE Power Engineering Society General Meeting, USA, Denver, 2004.

[3] D. Wu and J. W. Zhang, "Control System of VariAble-speed Permanent-magnet Generator Directly Driven by Wind Turbine,” Large Electric Machine and Hydraulic Turbine, No. 6, 2006, pp. 51-55.

[4] M. Yin, G. Y. Li and J. C. Zhang, et al., "Modeling and Control Strategies of Directly Driven Wind Turbine with Permanent Magnet Synchronous Generator,” Power System Technology, Vol. 31, No.15, 2007, pp. 62-65.

[5] H. L. Tsai, C. S. Tu and Y. J. Su, "Development of Generalized Photovoltaic Model Using Matlab/Simulink," Proceedings of the World Congress on Engineering and Computer Science, 2008.

[6] Z. Y. Sun, H. Yu and G. G. Yan, "PSCAD Simulation Models for Photovoltaic Array and MPPT Controller," Power System Protection and Control, Vol. 37, No.19, 2009, pp. 61-64.

[7] W. I. Rowen, "Simplified Mathematical Representations of Heavy Duty Gas Turbines,” Journal of Engineering for Power, Vol. 105, No.4, 1983, pp. 865-869. doi:10.1115/1.3227494

[8] G. G. Yan, J. G. Liu and G. Mu, "Modeling and Control 
Strategies of Directly Driven Wind Turbine with Permanent Magnet Synchronous Generator," Power System Protection and Control, Vol. 39, No.7, 2011, pp. 68-73.
[9] C. S. Wang, F. Gao and P. Li, "Model Improvement and Experimental Verification of Microturbine Generation System,” Journal of Tianjin University, 2011. 